\title{
Preliminary study on tensile and impact properties of kenaf/bamboo fiber reinforced epoxy composites
}

\begin{abstract}
The application of natural fibers as reinforcement in composite material has increased due to environmental concerns, low cost, degradability and health concerns. The purpose of this study is to identify the best type of bamboo fibers to be used as reinforcement for kenaf $(\mathrm{K}) / \mathrm{bamboo}$ hybrid composite. There were three types of bamboo fibers evaluated in this study which include bamboo mat (B), bamboo fabric (BF) and bamboo powder (BP). Chemical composition of $\mathrm{B}, \mathrm{BF}, \mathrm{BP}$ and $\mathrm{K}$ fibers were analyzed in this study. The effect of different types of bamboo fibers on tensile, impact, and morphological properties were investigated. The B/epoxy composites displayed the highest tensile strength (53.03 MPa) while K/epoxy composite had the highest tensile modulus $(4.71 \mathrm{GPa})$. Scanning electron micrographs of B/epoxy composites displayed better fiber/matrix interfacial bonding in comparison to other studied composites. Results showed that impact strength of BF-based composite was highest $(45.70 \mathrm{~J} / \mathrm{m})$. In conclusion, the tensile strength of B/epoxy composite is superior to the other bamboo reinforced composites and will be further evaluated in the next study.
\end{abstract}

Keyword: Composite; Kenaf; Bamboo; Natural fiber polymer composite; Tensile properties; Impact properties; Morphological properties 